\title{
Claudio Monteverdi: Disonancia y a(e)fecto
}

\section{Artículo de investigación}

\section{Gabriel Mora-Betancur}

Universidad Incca de Colombia

moragabo@gmail.com

Recibido: 5 de junio de 2019

Aprobado: 25 de julio de 2019

Cómo citar este artículo: Mora-Betancur, Gabriel (2020). Claudio Monteverdi: Disonancia y a(e)fecto. Calle 14: revista de investigación en el campo del arte 15(28). pp. 338-353. https://doi.org/10.14483/21450706.16276

\section{(2) (1)}

https://creativecommons.org/licenses/by/4.0/deed.es 


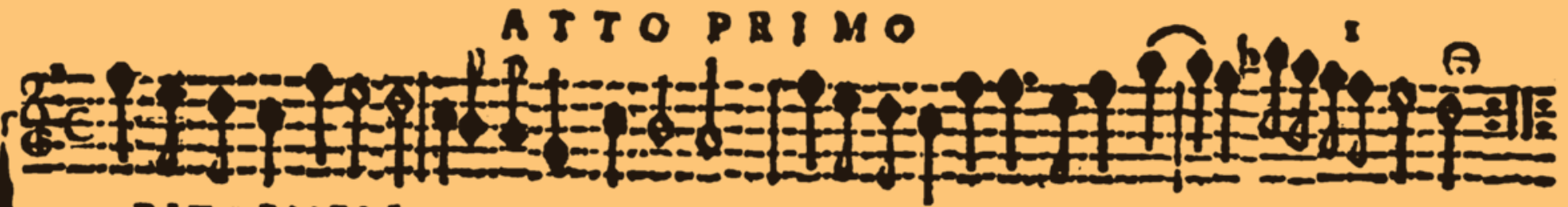
RITORNELLC)

SES (n)

EFive:

\section{P R O L O G O}

i A M V S C A.

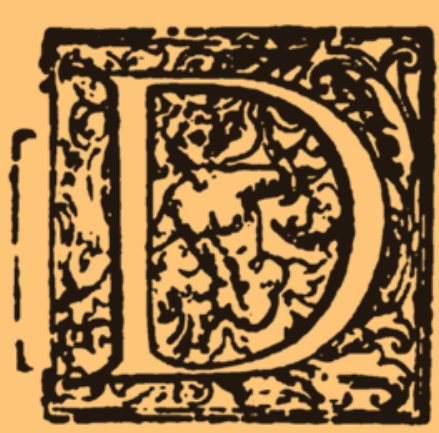

(1) Almio permctios mato a uoine uegno Inclizi Eroi



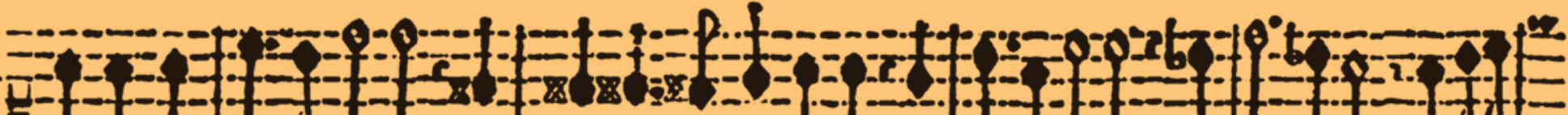

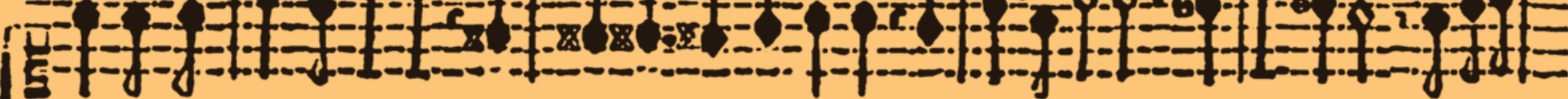
Eanguegenuil de Rcgi Di cuinarra lafumma ec celfi pregi Negiügealuer perchèerop

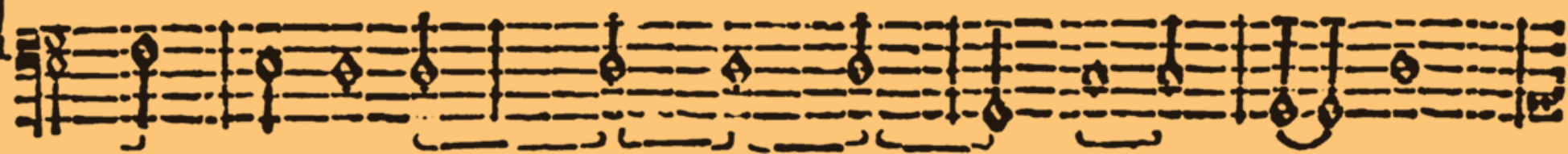

(ี)

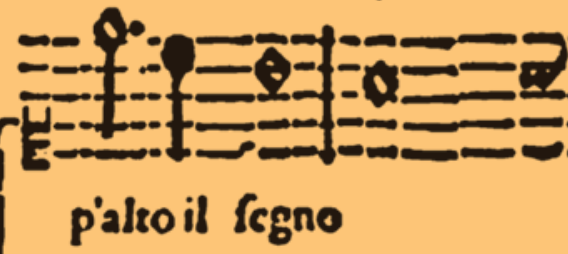

Ritomello 


\title{
Resumen
}

El presente texto plantea una reflexión entre el uso de las disonancias por Claudio Monteverdi y la idea de sujeto sensible durante la primera mitad del siglo XVII. Para dicho propósito se realiza una revisión de las categorías propuestas por Christoph Bernhard en su Tractatus compositionis augmentatus (1660). A manera de cierre, se espera que se pueda hacer notoria la relación entre los conceptos de afectos o pasiones y las disonancias empleadas por Monteverdi.

\section{Palabras claves}

Afectos; disonancia; Monteverdi; sujeto.

\section{Claudio Monteverdi: Dissonance and A(E)ffect}

\begin{abstract}
We offer a reflection about the use of dissonances by Claudio Monteverdi and the idea of the sensitive subject during the first half of the 17th century. For this purpose, we review the categories proposed by Christoph Bernhard in his Tractatus compositionis augmentatus (1660). In the conclusion, the relationship between the concepts of affections or passions and the dissonances used by Monteverdi will be made explicit.
\end{abstract}

\section{Keywords}

Affections; dissonance; Monteverdi; subject.

\section{Claudio Monteverdi: dissonance et a(e)ffection}

\section{Résumé}

Nous présentons une réflexion sur l'utilisation des dissonances par Claudio Monteverdi et sur l'idée de sujet sensible dans la première moitié du XVIIe siècle. A cet effet, nous faisons une revue des catégories proposées par Christoph Bernhard dans son Tractatus compositionis augmentatus (1660). Nous espérons que la relation entre les concepts d'affections ou de passions et les dissonances utilisées par Monteverdi devendra explicite.

\section{Mots clés}

Affections ; dissonance ; Monteverdi ; sujet.

\section{Claudio Monteverdi: Dissonância e afeto/efeito}

\section{Resumo}

O presente texto propõe uma reflexão entre o uso das dissonâncias utilizadas por Claudio Monteverdi e a ideia de sujeito sensível durante a primeira metade do século XVII. Para este propósito se realiza uma revisão das categorias propostas por Christoph Bernhard em seu Tractatus compositionis augmentatus (1660). A modo de fechamento, se espera fazer notória a relação entre os coitos de afetos ou paixões e as dissonâncias utilizadas por Monteverdi.

\section{Palavras chaves}

Afetos, dissonância, Monteverdi; sujeito. 


\section{Maillallachiska}

Kai mailla kilkaipi munaku iuiachingapa imami jiru ullari aikumi kai runa Claudio Monteverdi suti, kawachiku kai watakunapi XVII. Kaikuna rurangapa, llukami achika kawangapa sug runawa suti Christoph Bernhard kasa suti rurai tractatus compositionis augmentotus ña tukuchingapa munakumi ningapa imasami nuka kawaskani kaiskai parlukuna ruraska kai runa.

\section{Rimangapa Ministidukuna}

Munai sugkunata; giru ullachii; chasa suti runa; chi pai kuna. 
El presente texto se plantea como una reflexión sobre aquellas sonoridades catalogadas como disonancias que fueron utilizadas a principios del siglo XVII por el compositor italiano Claudio Monteverdi. Esta inquietud con respecto a las disonancias no se queda en la mera especulación en cuanto a su uso, teoría y surgimiento, sino, que se pretende indagar en qué manera estas y la teoría de los afectos empleada por los pensadores de la época antes mencionada se podrían vincular entre sí. Es posible que la idea de afectos haya modificado la forma en que la música hacía uso de las disonancias y de las texturas musicales, o que simplemente el uso de estas nuevas herramientas hayan recibido mayores posibilidades de explotación artística vinculándolas a la teoría de los afectos. Lo anterior debido a que el concepto de afectos, o pasiones, no surge en el siglo XVII, sino mucho antes.

A partir de las ideas antes expuestas, el presente texto se encuentra articulado en tres apartados. El primero se ocupa de las disonancias de manera teórica y práctica enfatizando en las que hacen parte de la llamada seconda prattica propuesta por el propio Monteverdi; el segundo aborda directamente la teoría de los afectos desde diferentes disciplinas, para converger finalmente en la música y el uso de la disonancia. Con base en esta indagación, el tercer apartado espera generar un aporte sobre la construcción de una idea subjetiva de los afectos en el siglo XVII que pudiera ser representada por medio de la música e identificada como tal tanto por intérpretes como espectadores. Todo lo cual podría desembocar en la construcción de un ideal colectivo relacionado a qué es ser un sujeto que es afectado por pasiones.

\section{Disonancias a principios del siglo XVII}

Realizar un análisis estético de las practicas que se dieron durante el siglo XVII de una manera concienzuda, sería una empresa que superaría por mucho el ámbito y los alcances del presente texto. . El propósito aquí es el de indagar sobre las practicas disonantes llevadas a cabo por Monteverdi y ver si éstas responden a ciertos ideales teóricos. Teniendo en cuenta lo anterior se podría decir que una de las principales características, más no la única, de la música de comienzos del siglo XVII fue el cambio del manejo de las disonancias con respecto a la estética precedente, la del Renacimiento. Ya que éstas eran principalmente justificadas según el afecto que pudiera transmitir el texto que estuvieran acompañando. Como manifiesta Bukofzer (1947):
The fundamental turn from intervallic to chordal harmony, from prepared to unprepared dissonance, took place around 1600. Dissonances, notably sevenths and ninths, needed no preparation, if justified by affective words such as crudo, acerbo, lasso, and all the other household words of the madrigal vocabulary. The chromaticism of the earlier madrigal had paved the way for melodic dissonances, but even the daring and highly chromatic madrigals of Cipriano de Rore and the startling enharmonic ventures of Marenzio were couched in terms of triads and the traditional dissonance treatment. It is only in the works of the Prince Gesualdo di Venosa (c. 1560-1614) that the madrigal went through its crisis. $^{1}$ (Bukofzer, 1947, pp. 33-4)

Como se puede observar es durante la primera mitad del siglo XVII que los compositores empiezan una exploración sistemática sobre los posibles usos de las disonancias con el fin primordial de poder expresar los afectos contenidos por las palabras, resaltándolas por medio del sonido. Lo anterior, llevó a que los compositores se alejaran gradualmente de las reglas de escritura y, por consiguiente, del uso de las disonancias de la estética renacentista. Un ejemplo de lo antes mencionado es que ya no era obligatorio resolver todas las disonancias de manera descendente; o que éstas fueran tratadas sobre partes débiles a manera de disonancias que transitan entre consonancias establecidas en partes fuertes, llamadas por Berhard como Transitus. Siguiendo todavía a Bukofzer (1947):

The bass, which in baroque music supplied the chords, thus enabled the upper voices to form dissonances more freely than before. The resolution of the dissonance could be effected by leading the dissonant voice to the next chord tone by either downward or upward motion. This alternative illustrates the new melodic freedom of baroque music, which was no longer bound

\footnotetext{
1 El giro fundamental de la interválica a la armonía acórdica, de la disonancia preparada a la disonancia no preparada, tuvo lugar hacia 1600. Las disonancias, especialmente las séptimas y novenas, no necesitaban preparación, si se justificaban con palabras afectivas como crudo, acerbo, lasso y todas las demás palabras familiares del vocabulario madrigalista. El cromatismo del madrigal anterior había allanado el camino para las disonancias melódicas, pero incluso los atrevidos y muy cromáticos madrigales de Cipriano de Rore y las sorprendentes aventuras armónicas de Marenzio fueron formuladas en términos de tríadas y el tratamiento tradicional de disonancia. Solo en las obras del príncipe Gesualdo di Venosa (c. 1560-1614) el madrigal atravesó su crisis. (Todas las traducciones son del autor).
} 
to the renaissance rule to resolve all dissonances by descending motion.2 (Bukofzer, 1947, p. 10)

Aquí es difícil afirmar si es debido a la nueva exploración de las disonancias que la línea melódica del bajo comienza a adquirir más importancia o si es la consideración vertical de las partes la que permite una nueva exploración de las mismas.

Como lo manifiesta anteriormente Bukofzer, esta nueva línea instrumental también brindaba la posibilidad de otras voces que no hacían parte de la representación gráfica de la música pero que sí existían en la práctica sonora. Lo anterior, pudo haber permitido incluso una mayor exploración de las disonancias teniendo presente que podrían existir más voces implicadas en la elaboración del continuum musical. De acuerdo a Bukofzer (1947):

Unlike the monodists Monteverdi approached his stylistic crisis through the madrigal. Like the Camerata, he laid down the axiom of the dominance of the words over the harmony (see the postscript to his Scherzi musicali), but it led to a diametrically opposed result because he applied it to polyphony, not against it, as the Florentines did. Monteverdi thus appears as a Janus-faced composer between two eras, conservative with regard to the preservation of polyphony in principle, but revolutionary with regard to its transformation in practice. $^{3}$ (Bukofzer, 1947, p. 33)

En los siguientes apartados se tratarán dos tipos de procedimientos concernientes al uso de las disonancias, basados en lo propuesto por Christoph Bernhard (1627-92) en su Tractatus compositionis aumentatus

2 El bajo, que en la música barroca proporcionaba los acordes, permitía que las voces altas formaran disonancias más libremente que antes. La resolución de la disonancia podría ser efectuada conduciendo la voz disonante al siguiente tono de acordes, ya sea hacia abajo o hacia arriba. Esta alternativa ilustra la nueva libertad melódica de la música barroca, que ya no estaba ligada a la regla del renacimiento para resolver todas las disonancias mediante el movimiento descendente.

3 A diferencia de los monodistas, Monteverdi abordó su crisis estilística a través del madrigalismo. Como la Camerata, puso el axioma del dominio de las palabras sobre la armonía (ver el colofón de su Scherzi musicali), pero condujo a un resultado diametralmente opuesto porque lo aplicó a la polifonía, no contra ella, como lo hicieron los florentinos. Monteverdi aparece así como un compositor con dos caras entre dos eras, conservador en cuanto a la preservación de la polifonía en principio, pero revolucionario en cuanto a su transformación en la práctica.
(1660). Se exponen estos dos tipos de procedimiento, ya que son característicos del uso de la disonancia propuesto por Monteverdi y se alejan de las prácticas de la estética renacentista. Antes de proseguir vale la pena aclarar que no se hablará del contexto cromático, ya que Bernhard lo expone como un fenómeno horizontal, llamado passus duriusculus, sin realización vertical en una textura monódica, lo que nos alejaría del contexto disonante en el que se quiere profundizar. Sin más preámbulos, el primer tipo de procedimiento, concierne a una idea de textura a dos partes en la que una voz realiza el procedimiento disonante: a este procedimiento Bernhard lo denomina sincopatio. El segundo, se aproxima más a un concepto del manejo de las disonancias a más de dos partes, llamada por Bernhard heterolepsis. En donde los procedimientos de preparación, resolución y ejecución de la disonancia implican más de dos líneas melódicas de manera simultánea, aunque su escritura sea solo a dos voces.

\section{Tipos de sincopatio}

El presente apartado abordará el concepto de síncopa expuesto por Bernhard a partir de dos marcos referenciales diferentes. El primero, llamado stylus gravis, en donde a la síncopa simplemente se llamará sincopatio, y hace parte de la tradición renacentista y; el segundo, llamado stylus luxurians, en el cual se hablará de cuatro tipos de síncopas. Estas cuatro síncopas son catalogadas en dos grupos, tres síncopas harán parte de lo que Bernhard denomina sincopatio catacrestica y la restante se llamará mora.

\section{Stilus Gravis - sincopatio}

Este tipo de síncopa deberá ser preparada por medio de una consonancia en la parte débil para posteriormente convertirse en disonancia en la parte fuerte siguiente. Después de haber sido escuchada como disonancia la voz que realiza la síncopa deberá resolver siempre de manera descendente a una consonancia.

Por otro lado, si la síncopa es realizada por la parte superior, la voz inferior podrá quedarse quieta, subir una segunda o saltar por intervalo de cuarta ascendente,

\section{EXAMPLE I 76}

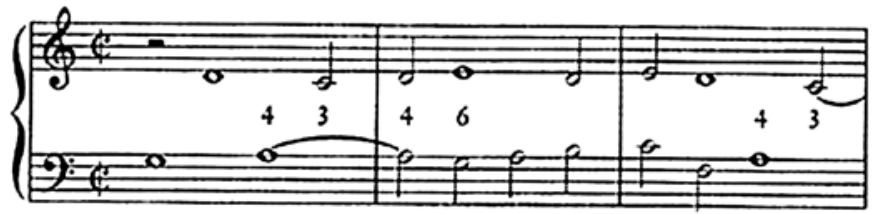

Imagen 1. Tomado de Bernhard (1660) 
de quinta descendente o, en muy raras ocasiones, de tercera descendente. Si la síncopa se encuentra en la parte inferior, la voz superior deberá permanecer quieta hasta que se haya resuelto la disonancia.

\section{Stylus luxurians, sincopatio catacrestica y mora}

En este apartado se puede apreciar un uso de la síncopa que fue novedoso para la primera mitad del siglo XVII y que es también una de las principales diferencias entre la escritura musical de lo que Monteverdi denominó como la prima prattica y su estilo, llamado por él mismo como, seconda prattica. ${ }^{4}$

Para empezar, se abordará lo que Berhard ha denominado como sincopatio catacrestica. La característica principal de este tipo de síncopa es que no resuelve de la manera expuesta por el stylus gravis. En donde la síncopa es preparada por un intervalo consonante que posteriormente se transforma en uno disonante para finalizar en otro consonante. A continuación se expondrán cada uno de los tres casos de acuerdo a las descripciones dadas por Bernhard:

En el primer tipo la voz que realiza la síncopa sí desciende una segunda, pero no resuelve a un intervalo armónico consonante, por el contrario, finaliza con otra disonancia. Bernhard plantea que este tipo de resolución se da cuando una séptima en síncopa resuelve en una quinta disminuida.

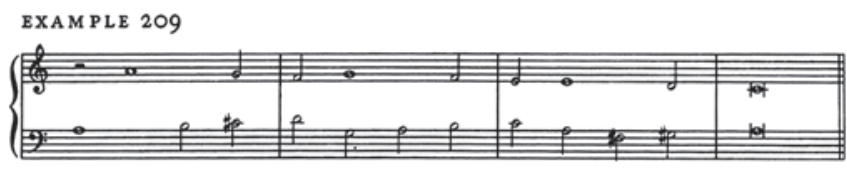

Imagen 2. Tomado de Bernhard (1660)

El segundo tipo consiste en que el intervalo que da inicio a la síncopa no es consonante. Cosa que sí sucede en el stylus gravis.

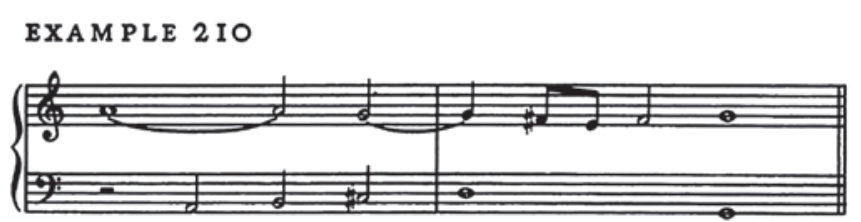

Imagen 3. Tomado de Bernhard (1660)

$4 \quad$ Bernhard llama al primero stylus gravis y al segundo stylus luxurians.
El tercer, y último, tipo de sincopatio catacrestica consiste en preparar y producir el intervalo disonante como en el stylus fravis. Sin embargo, lo que es diferente con respecto al stylus gravis es la manera en que resuelve el intervalo consonante, ya que no se da por grado conjunto descendente sino por salto descendente.

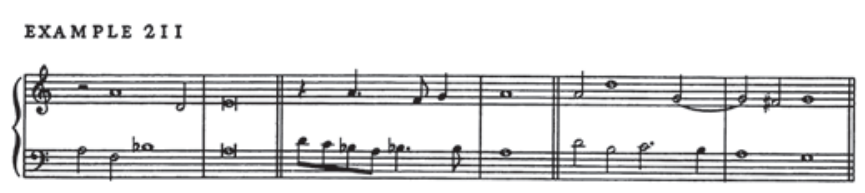

Imagen 4. Tomado de Bernhard (1660)

Por último, existe otro tipo de síncopa llamada mora. La principal diferencia entre esta síncopa y la del stylus gravis es que la mora resolverá siempre por intervalo de segunda ascendente y nunca descendente.

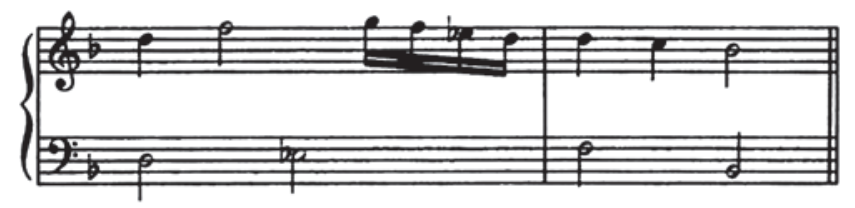

Imagen 5. Tomado de Bernhard (1660)

Se puede observar que el uso de la síncopa en la seconda prattica, o stylus luxurians, se diferencia principalmente de las antiguas normas de escritura a causa de la resolución o la preparación por medio de una disonancia.

Es interesante reflexionar sobre la aparición y uso de este tipo de síncopas en la música de Monteverdi. Lo anterior, debido a que no se puede saber con certeza si la escritura de estas se deba, o no, a una práctica interpretativa que pudo no haber estado en un principio escrita, pero que los ejecutantes conocieran debido a una inmersión cultural y estética. Como sucedió con las notes inégales, las corcheas en el jazz y fenómenos similares en otros tipos de músicas.

\section{Heterolepsis}

Para Bernhard el procedimiento de heterolepsis, que también hace parte de la seconda prattica, consiste en una textura a más de dos voces pero que en el resultado escrito solo se pongan en evidencia dos de éstas, voz cantada y continuo. Es decir, hay una voz que ejecuta una línea melódica que en realidad es el resultado de varias, más el acompañamiento del continuo. De acuerdo con Bernhard se pueden encontrar dos tipos de heterolepsis: 
Cuando una voz llega a una disonancia por medio de un salto. Pudiendo haber sido realizada como una disonancia en grado conjunto por otra voz inexistente en la partitura.

EXAMPLE 237
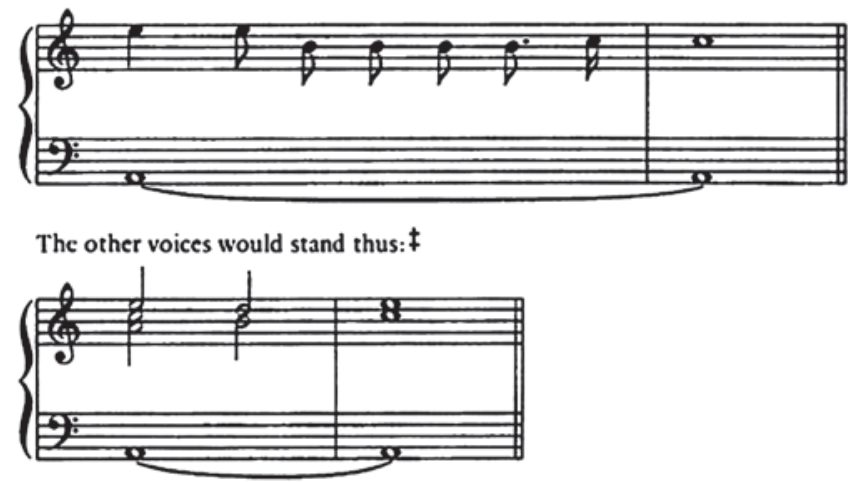

Imagen 6. Tomado de Bernhard (1660)

El segundo tipo de heterolepsis, consiste en que la voz inferior realice una síncopa y la voz superior, generando un intervalo armónico de cuarta aumentada, no resuelva una segunda ascendente, sino que descienda una tercera.

\section{EXAMPLE 24 I}
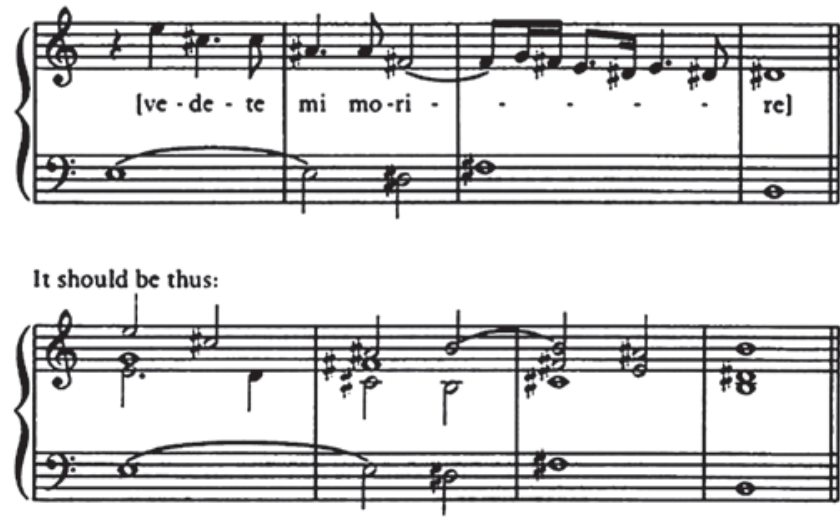

Imagen 7. Tomado de Bernhard (1660)

En resumen, este procedimiento consiste en aplicar las preparaciones y resoluciones de las disonancias de manera habitual en una textura a más de dos voces. Sin embargo, lo que se presenta es una textura a dos en donde las disonancias no se perciben de una manera que podría haber sido habitual para una escucha proveniente de una tradición renacentista.
Aunque Bernhard, y mucho menos Monteverdi, no hace referencia a los orígenes de la heterolepsis. Esta pudo haber sido una práctica común entre los instrumentistas de la época conocida como ornamentación alla bastarda en donde una textura a varias voces es ejecutada por un instrumento melódico de manera que este va tomando prestado lo que más le convenga de cada voz y generando así una nueva línea melódica.

Aduierta el q hiziere prosession desa manera del tañer q es differente de lo que tratamos en el primer libro que es tañer en concierto con quattro o cinco vihuelas, por que alli es necessario para q sea bien hecho que el contrapunto sea siempre a proposito de a quella boz que tañe. por que siempre ha de yr Subiecto a ella, por evitar el error en que algunos incurren divertiendose en hazerlo que les parece dexando el sibiecto prinicpal que es la boz compuesta. Mas en esta manera de tañer no es necessario yr atado siempre a vna boz, por que a vn q el subiecto principale ha deser el contrabaxo lo que puede dexar y tañer sobre el tenor o contralto, o suprano come meyor le pariziere tomando de cadauno lo que mas le viniere a proposito. $Y$ la razon delto es por que el Cymbalo tanne la obra perfettamente con todas sus bozes, y lo que haze el Violon es accompannar y dar gracia a lo que el Cymbalo tanne, deleytando con el differenciado sonido de la cuerda los oyentes. ${ }^{5}$ (Ortiz, 1553, pp. 37-8)

\section{Entre sincopatio catacrestica y heterolepsis}

Pese a los esfuerzos realizados por Bernhard al tratar de evidenciar el uso de las disonancias implementado por Monteverdi, se podría hablar de una categoría intermedia. Esta categoría estaría en una especie de limbo conceptual entre lo que se ha podido definir en los apartados anteriores como sincopatio catacrestica y heterolepsis. Lo anterior debido al orden de sucesión de las disonancias. En los ejemplos utilizados por Bernhard las disonancias en sincopatio catacrestica pueden ser

$5 \quad$ Advierta el que hiciere profesión de esta manera del tañer que es diferente de lo que tratamos en el primer libro que es tañer en concierto con cuatro o cinco vihuelas, porque allí es necesario para que sea bien hecho que el contrapunto sea siempre apropósito de aquella voz que tañe. Porque siempre ha de ir sujeto a ella, por evitar el error en que algunos incurren divirtiéndose en hacerlo que les parece dejando el sujeto principal que es la voz compuesta. Más en esta manera de tañer no es necesario ir atado siempre a una voz, porque, aunque el sujeto principal ha de ser el contrabajo lo que puede dejar y tañer sobre el tenor o contralto, o como mejor le pareciere tomando de cada uno lo que más le viniere apropósito. Y la razón de esto es porque el cymbalo tañe la obra perfectamente con todas sus voces, y lo que hace el violón es acompañar y dar gracia a lo que el cymbalo tañe, deleitando con el diferenciado sonido de la cuerda los oyentes. 
preparadas por un intervalo disonante y resueltas sobre uno consonante, o después de preparar una disonancia por medio de una consonancia se pueda continuar con otra disonancia, ver figuras 2 y 3 . Por otro lado, en cuanto a la heterolepsis, las disonancias siempre van preparadas y resueltas por una consonancia, ver figuras 7 y 8 . ¿pero qué sucede cuando el orden de las disonancias y consonancias se aproxima al concepto de sincopatio catacrestica pero su explicación es lograda por medio del de la heterolepsis?

En la Imagen 8, tomada de segundo acto de L'Orfeo, se pude observar tres disonancias consecutivas sin ningún tipo de preparación. No obstante, el proceso disonante sí resuelve sobre un intervalo consonante.



Imagen 8. L'Orfeo segundo acto "Mai più non tornare".

Sin embargo, este uso de las disonancias pude llegar a ser explicado si se recupera el concepto de heterolepsis de una manera un poco más flexible. Como se muestra en la Imagen 9.

\section{Act II}

Mai più non tornare

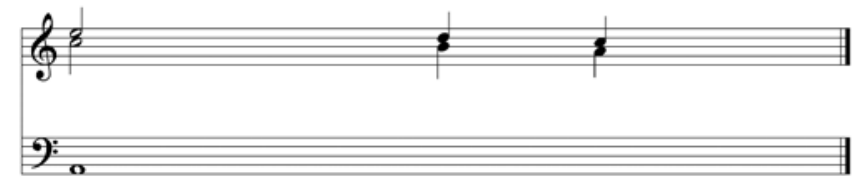

Imagen 9. Realización en entre sincopatio catacrestica y heterolepsis.

Como se puede observar en la Imagen 9, las disonancias antes expuestas tendrían razón de ser desde la alternancia de una voz inexistente en la partitura y dislocación temporal en la aparición de las mismas.

En la Imagen 10, de acuerdo con las categorías expuestas por Bernhard las disonancias utilizadas por Monteverdi no tendrían una posible explicación.

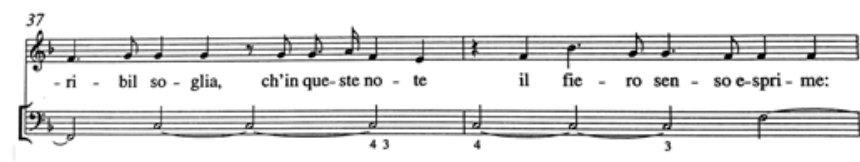

Imagen 10. Tercer acto "Speranza" compás 38.
Sin embargo, una de las posibles explicaciones al uso de la disonancia es el retomar los conceptos de sincopatio catacrestica y heterolepsis antes expuestos y combinarlos de una manera un poco más flexible. Ver Imagen 11.

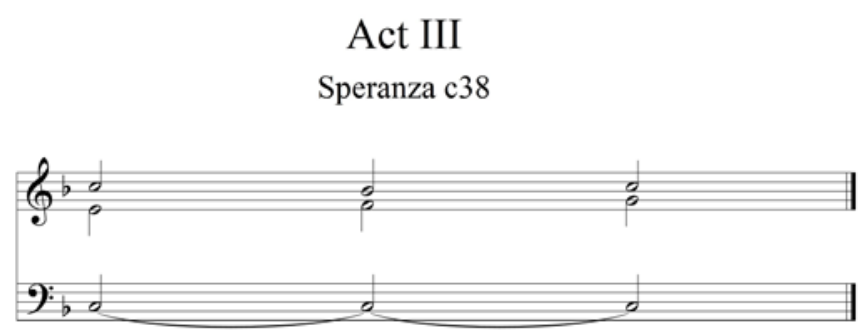

Imagen 11. Realización en entre sincopatio catacrestica y heterolepsis.

Pese a lo expuesto en este apartado, Bernhard sí realiza un vínculo explícito de los conceptos de sincopatio catacrestica y heterolepsis. No obstante, solo relaciona estos dos conceptos cuando concuerdan con el orden de aparición de las disonancias. Es decir, una disonancia preparada y resuelta por consonancia podría llegar a ser interpretada bien sea como sincopatio catacrestica o como heterolepsis. Ver Imagen 4.

\section{Afecto y pasión en la primera mitad del siglo XVII}

La idea de afectos, o pasiones ${ }^{6}$, en la música ha sido ampliamente abordada y tratada por diferentes teóricos en diversos periodos históricos. No obstante, es durante el siglo XVII que se producen un gran número de textos en torno a la teoría de los afectos en la música; y durante ese mismo periodo el compositor Claudio Monteverdi empieza su producción madura y experimentación monódica. Por lo tanto, el objetivo principal del presente apartado es evidenciar qué elementos musicales fueron utilizados por Monteverdi como medio de representación de los afectos.

\section{Afecto y música en la primera mitad del siglo XVII}

Aquí me centraré principalmente en la primera mitad del siglo XVII debido a que es durante este periodo que se dan grandes avances en el tránsito del concepto de afecto, proveniente de la retórica, a la música. Como lo afirma López-Cano (2015) “A partir de 1535, pero sobre todo desde 1599 y hasta 1792, teóricos musicales

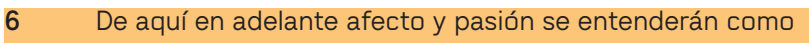

sinónimos. 
centroeuropeos importaron sistemáticamente términos, conceptos y estrategias de la antigua retórica clásica al estudio de diversos aspectos de la música." (p. 15)

Este tránsito de conceptos de la retórica a la música fue de gran interés para la camerata florentina en Italia, sobre todo en el género llamado recitativo. Como manifiesta Bukofzer: "La Camerata [Florentina] justificó la introducción del recitativo continuo sobre la teoría de que la música debe imitar la entrega de un orador y su forma de mover los afectos del público." 7

Podemos evidenciar lo anterior en las palabras de Caccini:

Pero, puesto que nunca he descansado en silencio dentro de los límites ordinarios utilizados por los demás, sino que siempre he seguido buscando más novedad en la medida de lo posible, siempre que la novedad haya sido adecuada para poder lograr mejor el objetivo del músico, es decir, deleitar y conmover los afectos del alma. ${ }^{8}$

Cuando los compositores de la primera mitad del siglo XVII hablaban de afectos, se referían a los más violentos y abruptos, siendo esta concepción de los afectos una total novedad para la época, ya que este tipo de referencias no eran utilizadas por los compositores del renacimiento. Recordemos que estos últimos sí conocían las teorías sobre los afectos y también habían reflexionado sobre los mismos. Sin embargo, los puntos de vista entre los compositores de estos dos periodos eran totalmente diferentes.

Los afectos que estaban interesados en representar $y$, obviamente, producir los compositores de este periodo requerían de un cambio drástico en lo que respecta a las reglas de escritura musical. Las variaciones más notorias en las reglas de escritura renacentista y del barroco temprano se evidencian sobre todo en dos aspectos principales, el primero la construcción melódica como lo menciona Bukofzer:

$7 \quad$ "The Camerata justified the introduction of the continuous recitative on the theory that music should imitate the delivery of an orator and his manner of moving the affections of the audience." (Bukofzer, 1947, p.7)

8 Ma perche io non mi sono mai quietato dentro ai termini ordinari, e usati da gli altri, anzi sono andato sempre investigando più novità à me possibile, pur che la novità sia stata atta à poter meglio conseguiré il fine del musico, cioè dilettare, e muovere l'affetto dell'animo. (Caccini, 1602, p. 6)
El nuevo tipo de melodía se diferenciaba de la melodía renacentista principalmente por su estructura interna y su ritmo. Las limitaciones impuestas al compositor renacentista en cuanto a los saltos ascendentes y descendentes ya no eran válidas. El nuevo tratamiento de la disonancia implicaba también nuevos intervalos melódicos. Los pasos cromáticos $\mathrm{y}$, sobre todo, las progresiones aumentadas y disminuidas fueron los rasgos distintivos del estilo barroco temprano. Todos estos intervalos fueron probados experimentalmente en el último madrigal que condujo desde el renacimiento hasta el barroco. ${ }^{9}$ (Bukofzer, 1947, p. 11)

Y el segundo radicaría en el uso de las disonancias, lo que haría alusión directa a la seconda prattica de Monteverdi:

En esta fase las tendencias dramáticas y expresivas, siempre latentes en la forma, fueron empujadas a extremos afectivos. Estos revelan una concepción de la disonancia que ya no concuerda con las ideas renacentistas, como Monteverdi reconoció cuando habló de la seconda prattica en la música. Él y su seguidor, el teórico Berardi, insistieron en el hecho de que el nuevo tratamiento de la disonancia era la esencia del nuevo estilo. ${ }^{10}$ (Bukofzer, 1947, p. 33)

O como afirman Carter, S. \& Kite-Powell, J:

Estudios recientes también documentan que las disonancias extremas, no preparadas y no resueltas, así como la acciaccatura y otras características similares, fueron ampliamente usadas en

$9 \quad$ The new type of melody differed from renaissance melody mainly in its internal structure and its rhythm. The limitations imposed on the renaissance composer as to upward and downward skips were no longer valid. The new dissonance treatment implied also new melodic intervals. Chromatic steps and, especially, augmented and diminished progressions were the earmarks of the early baroque style. All of these intervals were experimentally tested in the late madrigal which led from the renaissance to the baroque. 10 N.T: In this phase the dramatic and expressive tendencies, always latent in the form, were pushed to affective extremes. These reveal a conception of dissonance no longer consistent with renaissance ideas, as Monteverdi recognized when he spoke of the seconda prattica in music. He and his follower, the theorist Berardi, insisted on the fact that the new dissonance treatment was the essence of the new style. 
Italia para transmitir mejor el efecto en la música vocal." ${ }^{11}$ (Carter, S. \& Kite-Powell, J, 2012, p. 328)

Para finalizar, este tipo de descripciones de los afectos en la primera mitad del siglo XVII nos podrían aproximar mucho al pensamiento de Spinoza (2015) cuando éste afirma que: "Un afecto no puede ni reprimirse ni quitarse sino por un afecto contrario y más fuerte que el afecto a reprimir" (p. 180) o como lo expresa Monteverdi (1638, p.2): "Sabiendo que los contarios [de pasiones, o afectos, del alma] son los que mueven en gran medida nuestro ánimo, fin que debe tener la buena música"12. Como se ha podido observar, son los afectos violentos, representados por uso de disonancias, cromatismos, intervalos melódicos aumentados y disminuidos, y no fórmulas melódicas preestablecidas lo que parece gobernar a la hora de representar dichas pasiones durante la primera mitad del siglo XVII. Esto se hará evidente durante los análisis de las obras de Monteverdi que se presentarán más adelante.

\section{Monteverdi y la representación de los afectos}

El apartado anterior nos da una posible idea al rededor concepto de afecto que pudieron llegar a tener algunos teóricos musicales de la época. No obstante, las ideas con relación a los afectos han sido en su gran mayoría de carácter teórico y en algunos momentos abstractas. Debido a lo anterior, vale la pena tratar de evidenciar cómo se daba el manejo de los afectos no solo desde un punto de vista teórico sino también desde la práctica musical propiamente dicha. A causa de esto, es que decidí abordar una composición y a un compositor bastante reconocidos del periodo, L'Orfeo (1607) de Claudio Monteverdi.

Para los fines del presente texto no se trabaja la obra en su totalidad, sino solo dos fragmentos recitativos. Primero, Orfeo en el segundo acto, cuando Euridice ha muerto, Tu se' morta. Se elige este fragmento, ya que es durante esta sección en donde Orfeo se entera de que su amada ha muerto y se encuentra desconsolado. Segundo, se tomará otro fragmento recitativo de Orfeo perteneciente al primer acto en el que él se encuentra rebosante de alegría y proclamando su amor y admiración por Euridice, Rosa del ciel. Se escogen estos

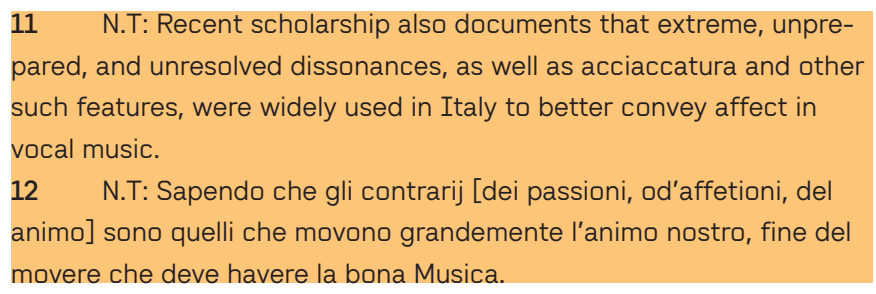

dos fragmentos recitativos porque contienen afectos opuestos, tristeza y alegría, y porque además son interpretados por el mismo personaje. A partir de estos análisis se busca evidenciar cuáles pudieron haber sido los medios musicales de los que disponía Monteverdi para representar los afectos. Lo anterior, teniendo en cuenta los conceptos teóricos recuperados en el apartado previo.

En la Imagen 12, en los dos primeros compases "tu se" morta" vemos cómo Monteverdi realiza un giro melódico disonante debido a la cuarta disminuida entre $B b$ y F\#, y más aún, cómo este $F \#$ es también una disonancia vertical con el $G$ del continuo. Esta disonancia podría ser tomada como una ornamentación melódica debido a su valor duracional, corchea, una variación de subsumptio. Sin embargo, un proceso similar ocurre cuando en el tercer compás "se' morta, mia vita," la voz realiza un movimiento ascendente $G \#, A$, $B$, en donde el $G \#$ y $B$ son disonancias contra el continuo en $A$. Aquí los valores duracionales no deben ser entendidos como posibles ornamentaciones melódicas.

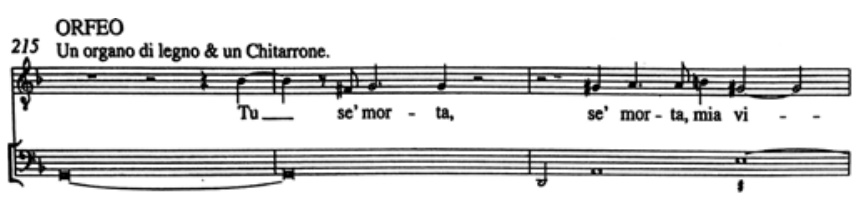

Imagen $12^{13}$. Orfeo, Tu se' morta, se' morta, mia vita. ${ }^{14}$

Todas estas disonancias son contrastadas rápidamente con una pequeña sección netamente consonante: "ed io respiro?". No obstante, rápidamente en los compases 219 a 220 Orfeo recuerda su tristeza "tu sei da me partita" en donde el F\# crea una evidente disonancia contra el continuo en $G$. Ver Imagen 13.

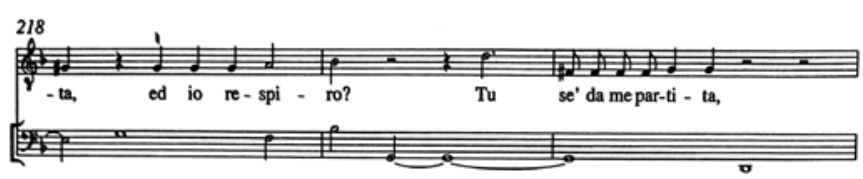

Imagen 13. Orfeo. ed io respiro? Tu se' da me partita, ${ }^{15}$

Podemos observar cómo esta sección disonante se prolonga hasta "se' da me partita per mai piú", Imagen 14 , en donde la voz, después de un silencio, realiza un

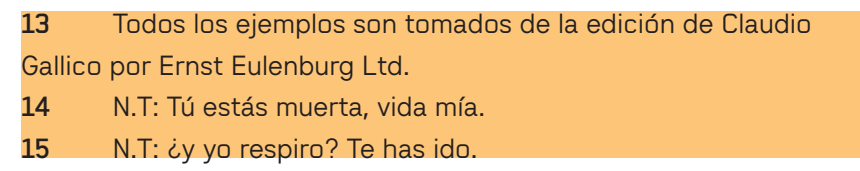


G\# contra un $A$ en el continuo, para posteriormente continuar con "mai piú non tornare, e dio rimango?" clara sección consonante.

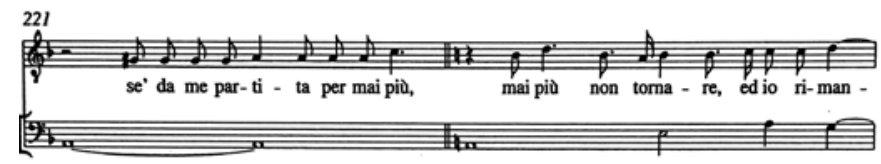

Imagen 14. Orfeo. se' da me partita per mai piú, mai piú non tornare, e dio rimango ${ }^{16}$

Como se ha mostrado hasta el momento, una de las estrategias de Monteverdi es contrastar frases consonantes con otras disonantes y viceversa. Recordemos la afirmación antes citada de Monteverdi en donde afirma que son los contrarios los que mueven nuestro ánimo. Esto se hace evidente cuando la sección anterior, netamente consonante, es contrastada por otra disonante. Ver Imagen 15.

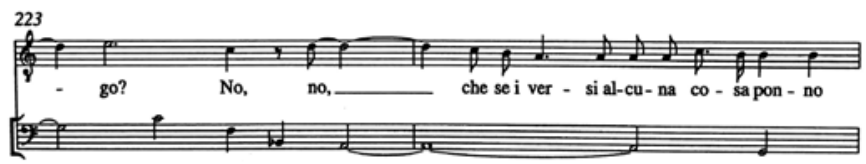

Imagen 15. Orfeo. No, no, che se i versi alcuna cosa ponno.

En esta nueva sección, Imagen 15, se puede apreciar la disonancia de cuarta formada por el $D$ en la voz y el $A$ en el continuo en la palabra "no" y por un flujo ininterrumpido de disonancias en el compás siguiente como lo es la continua aparición de $B$ en la voz en oposición al $A$ la parte del continuo.

En la Imagen 16 compás 226, podemos apreciar otro tipo de procedimiento armónico-melódico característico de Monteverdi y es el del uso de cromatismos. Como se puede apreciar en el descenso de $G \#$ a $G^{17}$ en la voz y de $B$ a $B b$ en el continuo.

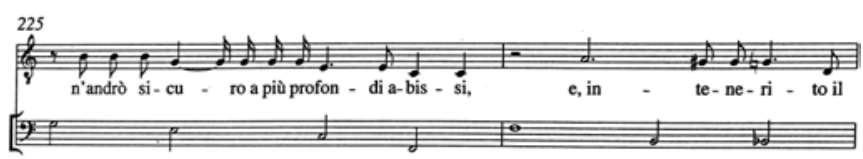

Imagen 16. Orfeo. Cromatismo en "intenerito il".

$16 \quad$ N.T: Para no volver jamás ¿y aquí permanezco?

17 La falta del becuadro en $G$ es error de la edición. Este sí aparece en el manuscrito.
A continuación, se procederá con el segundo análisis, un fragmento recitativo tomado del primer acto, Rosa del ciel.

En la Imagen 17, se puede observar que casi no aparecen disonancias. Ocasionalmente contrastan un $A$ y un $F$ en la voz contra el pedal en $G$ del continuo. Sin embargo, la preparación de estas disonancias es totalmente estable en cuanto al uso de disonancias provenientes del siglo XVI, ya que en su mayoría actúan como notas de paso o bordaduras. Un tránsito matizado y preparado de consonancia a disonancia para finalizar en consonancia.

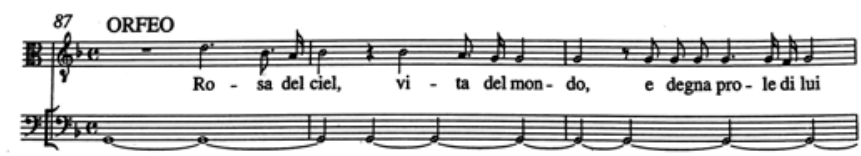

Imagen 17. Rosa del ciel, vita del mondo, e degna prole di lui.

El uso de las disonancias a lo largo de todo el recitativo, rosa del ciel, es consistente con lo expuesto para la Imagen 17. Sin embargo, vale la pena resaltar lo que ocurre bajo la frase tu sospirasti, Imagen 18, en donde el uso de la disonancia rompe con la regularidad expuesta antes. En la parte de la voz se canta un $\mathrm{C}$ a distancia de octava con el continuo, lo que posteriormente se tomara como preparación para desembocar en una disonancia a manera de suspensión. Hasta el momento esto no se alejaría de las técnicas renacentistas del uso de la disonancia. No obstante, al escuchar una disonancia preparada a manera de suspensión lo que se esperaría es que ésta resolviera por grado conjunto descendente. Sin embargo, Monteverdi toma la decisión de descender, pero no por intervalo de segunda sino por un salto de quinta a $\mathrm{F}$ lo que produce una nueva disonancia vertical de séptima entre el $F$ de la voz y el $G$ del continuo, el silencio de corchea podría ser interpretado como abruptio, que consiste en insertar un silencio en medio de una frase, sin embargo, aquí parece innecesario pensar en tal figura, ya que el abruptio solo se utilizaba en procesos cadenciales entre la tensión y la resolución de la cadencia, no siendo este el caso. Para finalizar este recorrido de disonancia a disonancia el intervalo de séptima se resuelve de la manera esperada sobre una consonancia vertical a la que se llega por grado conjunto descendente, intervalo de quinta justa entre el $E$ de la voz y el $A$ del continuo.

Hasta el momento podemos llegar a dos conclusiones: 1) Monteverdi no utiliza diseños melódicos como 


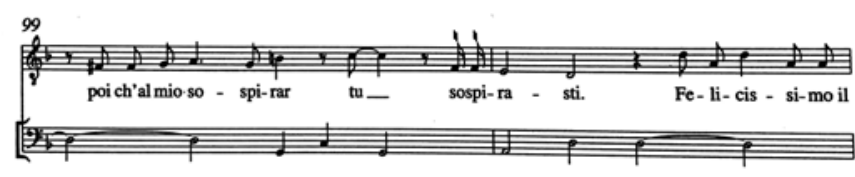

Imagen 18. Tu sospirasti.

elementos representativos de los afectos..$^{18}$ Esto porque el pensamiento disonante responde a relaciones verticales entre las voces y no a procesos netamente lineales a manera de evocar un afecto, como se ha podido observar en las imágenes 12 a 18, en donde no se manifiesta ningún tipo de perfil recurrente y; 2 ) Las principales disonancias ocurren en un contexto principalmente vertical. Éstas siempre acompañan palabras o frases que evocan algún tipo de estado de ánimo como tristeza "me has dejado", dolor "muerte" o anhelo "suspiraste". Aunque no se pueda hablar de un intervalo melódico definido como medio de representación de un determinado afecto, como por ejemplo una sexta menor descendente como representativo del lamento, aquí sí podemos reconocer ciertos tipos de procedimiento melódicos disonantes como lo son los intervalos disminuidos y aumentados, como sucede en la Imagen 12, y cromatismos, como se ve en la Imagen 16.

De lo anterior, se puede deducir que el principal recurso de representación de afectosutilizado por Monteverdi no consiste en fórmulas melódicas o armónicas sino en el procedimiento mismo de generar disonancias tanto verticales como horizontales. Podría ser esto lo que le dé una sonoridad diferente a cada recitativo que se encuentra en el Orfeo. Aunque, a pesar de todo, Monteverdi siempre logre evocar un afecto determinado sin recurrir al uso de un giro interválico recurrente a manera de leitmotiv.

\section{Reflexión}

El auge en la exploración sistemática de las disonancias no fue un acontecimiento aislado durante la primera mitad del siglo XVII, sino que hizo parte de una convergencia de diferentes inquietudes que rondaban las mentes de los compositores e intelectuales de la época. Un claro ejemplo de lo anterior es la gran cantidad de tratados musicales y filosóficos con relación al concepto de afecto que se produjeron durante el siglo XVII. En estos, se reflexionaba en gran medida en cómo

18 Se recomienda la lectura de "Música y retórica en el barroco" de Rubén López-Cano. el ser padecía pasiones y podría llegar a ser afectado por estímulos exógenos; siendo, en este caso particular, la música uno de los mismos. La idea de las pasiones indudablemente tuvo un afecto directo sobre las formas musicales y la manera de organizar el discurso sonoro fundamentándose principalmente en el devenir del texto, lo que desembocó en el género recitativo.

Otro posible acontecimiento que pudo haber promovido las nuevas exploraciones de las disonancias fue el pasar de una textura vocal polifónica de más de dos partes a una a solo dos, la monodia, en donde, la palabra llevada por la voz cantada era acompañada por una sola parte instrumental, lo que pudo haber facilitado la comprensión del texto y evidenciar de una manera más directa los procedimientos sonoros catalogados por sus actores como disonancias y consonancias. Aquí vale resaltar el auge de la práctica del bajo continuo que pudo haber facilitado nuevas maneras de exploración de las disonancias, como se ha querido demostrar previamente.

En relación a esas categorías, disonancia y consonancia, el tratado de Bernhard nos aproxima mucho al posible pensamiento que se tuvo de las mismas en la época. Aquí vale la pena resaltar que el texto de Bernhard no fue contemporáneo a la práctica de Monteverdi. Sin embargo, sí es un texto muy cercano a la misma y podría evidenciar cómo se fueron asentando cierto tipo de exploraciones en las que algunos procedimientos se conservaron, unos se transformaron y otros se descartaron. Es muy probable que debido a esto último pueda existir una categoría intermedia entre la sincopatio y la heterolepsis propuestas por Bernhard. Más aún, teniendo en cuenta que L'Orfeo es la primera composición en la que Monteverdi explora las posibilidades expresivas del recitativo, por lo que es muy probable que muchas de estas incursiones en la disonancia hayan sido variadas en el trascurso de los años y, en especial, de las obras mismas.

Es muy común que al realizar una sistematización de una práctica humana queden muchas variantes por fuera del sistema. Ya que si no se hiciera una depuración de dichas prácticas es muy probable que el sistema se volviera inmanejable y no pudiera conservar una idea general. Evidentemente, los estilos individuales son homogeneizados en una práctica común, por lo menos desde el punto de vista teórico. Y aquí vale la pena resaltar lo anterior, lo que se deja es una idea de la práctica no el ritual mismo del quehacer musical, en donde muchas otras cosas se dan de manera espontánea y no reflejada en la partitura en torno a un fin común. 
En lo que toca a las pasiones, para los compositores de la primera mitad del siglo XVII pudo llegar a ser muy atractiva la idea de afecto tomada de la retórica. Lo anterior, porque de ser posible transmitir afectos por medio de la música sería más factible el objetivo de deleitar, conmover y convencer a una audiencia, a lo que hace alusión Caccini. De ahí, probablemente, que el principal medio de expresión musical de los afectos durante este periodo fuera una forma poética, el recitativo. Este último se caracteriza principalmente por ser a una sola voz con un acompañamiento. En donde, estando el texto en la voz y las sonoridades verticales en el acompañamiento, pueden ser transmitidos los afectos de una manera directa y sin adornos, lo que probablemente facilitaría la comprensión de los escuchas. Es decir, sonido y lenguaje son transmitidos de una manera inmediata. Muy diferente a las prácticas vocales polifónicas del renacimiento en las que la compresión del texto y el traslape del mismo con otras voces pudiera generar confusión sobre la idea general que se pretendía transmitir por medio del mismo.

Es precisamente, a causa de lo anterior, que las obras que se tomaron para ser analizadas en el presente texto hacen parte de los recitativos que componen L'Orfeo de Claudio Monteverdi. Vale la pena aclarar que la obra citada, tiene diferentes momentos en donde surgen diversos tipos de combinaciones vocales e instrumentales.

Es de resaltar que los textos poéticos utilizados por los compositores de este periodo tienen en sí mismos la capacidad, o por lo menos el potencial, de producir afectos sin estar acompañados de música. Sin embargo, es posible que lo que pretendiera Monteverdi, y sus contemporáneos, no fuera solamente aprovechar el poder afectivo implícito en el texto, sino más bien potencializar su capacidad expresiva por medio de la música. Utilizando las disonancias melódicas y armónicas como medio sonoro para la representación de los afectos.

No obstante, aunque el uso de las disonancias haya podido ser un recurso utilizado por los compositores de la primera mitad del siglo XVII como medio para potencializar los afectos contenidos por el texto, estos habrían carecido de importancia si no pudieran haber sido reconocidos como tales por los escuchas de la época. De aquí la importancia de la disonancia en este periodo, ya que la estética predominante previamente establecida, el Renacimiento, tenía reglas bien definidas en cuanto a la preparación y resolución de las disonancias. Por lo tanto, es posible que los actores de estas músicas se encontraran habituados a cierto tipo de sonoridades las cuales fueran transgredidas por los compositores de principios del siglo XVII. A pesar de lo anterior, es también muy probable que a medida que se empezaran a asentar las disonancias los escuchas pudieran reconocer ciertas sonoridades como cargadas de afectos determinados. Así como hoy en día algunas personas siguen hablando de tonalidades menores como representantes de tristeza y las mayores como cargadas de alegría.

Para cerrar, vale la pena resaltar que para poder transmitir un mensaje, o en este caso un afecto, quienes hacen parte de una comunicación reciproca deben tener un contexto en común donde el mensaje pueda tener un significado mutuo para poder entenderse sin dificultades o errores de puntuación. Y aquí, hablando en términos generales, tal vez más cercano a nuestro tiempo, se podría decir que este contexto en común, o repertorio de reglas si se quiere, puede llegar a ser interiorizado por medio de prácticas culturales similares, como no hablar durante un concierto de cierto tipo de música, o construidas bajo la idea de lo que se pretende representar por medio de estas, como un cierto tipo de construcción de ideal nacionalista. Por lo tanto, la construcción de una identidad es siempre subjetiva y no es un proceso individualista sino más bien una creación colectiva en donde diferentes partícipes aportan algo para la construcción de un ideal en común. Lo que finalmente desemboca en reconocerse, ser reconocido y reconocer al otro como pertenecientes a una misma práctica.

\section{Referencias}

Bukofzer, M. (1947). Music in the baroque era From Monteverdi to Bach. W.W. Norton \& Company.

Bernhard, L. (1660). Tractatus compositionis augmentatus. Musica Iagellonica. Polonia.

Caccini, G. (1602). Le nuove musiche. Giorgio Marescotti, Florencia.

Carter, S. \& Kite-Powell, J (2012). A Performer's Guide to Seventeenth Century Music. Indiana University Press.

Deleuze, G. (2015). En medio de Spinoza. Cactus: Argentina. 
López-Cano, R. (2012). Música y retórica en el barroco. Universidad Autónoma de México.

Monteverdi, C. (1638) Madrigali libro ottavo. Alessandro Vincent. Venecia.

Ortiz, D. (1556) El libro primo nel qual si tratta della glose sopra le cadenze et altre sorte de punti in la musica de violone. Studio per edizioni scelte. Florencia.

Spinoza, B. (2015) Ética demostrada según el orden geométrico. México: Fondo de Cultura Económica. 